\title{
Pathogens and fecal indicators in waste stabilization pond systems with direct reuse for irrigation: Fate and transport in water, soil and crops
}

Verbyla, M.E. ${ }^{* 1, \dagger}$, Iriarte, M. ${ }^{2, \dagger}$, Mercado, A. ${ }^{2}$, Coronado, O. ${ }^{2}$, Almanza, M. ${ }^{2}$, Mihelcic, J.R. ${ }^{1}$

1 Department of Civil and Environmental Engineering, University of South Florida, 4202 E. Fowler Avenue, Tampa, Florida, United States

2 Centro de Aguas y Saneamiento Ambiental, Universidad Mayor de San Simón, Cochabamba, Bolivia

${ }^{\dagger}$ Indicates equal contribution to this work

* Corresponding Author, +1 860729 3189, verbylam@mail.usf.edu

\begin{abstract}
Wastewater use for irrigation is expanding globally, and information about the fate and transport of pathogens in wastewater systems is needed to complete microbial risk assessments and develop policies to protect public health. The lack of maintenance for wastewater treatment facilities in low-income areas and developing countries results in sludge accumulation and compromised performance over time, creating uncertainty about the contamination of soil and crops. The fate and transport of pathogens and fecal indicators was evaluated in waste stabilization ponds with direct reuse for irrigation, using two systems in Bolivia as case studies. Results were compared with models from the literature that have been recommended for design. The removal of Escherichia coli in both systems was adequately predicted by a previouslypublished dispersed flow model, despite more than 10 years of sludge accumulation. However, a design equation for helminth egg removal overestimated the observed removal, suggesting that this equation may not be appropriate for systems with accumulated sludge. To assess the contamination of soil and crops, ratios were calculated of the concentrations of pathogens and fecal indicators in soil or on crops to their respective concentrations in irrigation water (termed soil-water and crop-water ratios). Ratios were similar within each group of microorganisms but differed between microorganism groups, and were generally below $0.1 \mathrm{~mL} \mathrm{~g}^{-1}$ for coliphage, between 1 and $100 \mathrm{~mL} \mathrm{~g}^{-1}$ for Giardia and Cryptosporidium, and between 100 and 1,000 $\mathrm{mL} \mathrm{g}^{-1}$ for helminth eggs. This information can be used for microbial risk assessments to develop safe water reuse policies in support of the United Nations' 2030 Sustainable Development Agenda.
\end{abstract}

Keywords: sanitation; microorganisms; parasites; wastewater use; reclaimed water; WHO Guidelines 


\section{Introduction}

Waste stabilization ponds (WSPs) are frequently used for wastewater treatment in small cities, towns, and regions with a lot of land but limited financial capital, partly because they are resilient systems that perform well and remove pathogens with limited maintenance requirements (Mara, 2003). However, not all of these systems are well-maintained throughout their life cycles. The removal of sludge from primary WSPs is a capital maintenance expenditure required every 2 to 15 years (depending on the system design and solids loading rate). In low-income communities with WSP systems, the amortized cost of sludge removal is often not included in the annual operation and maintenance budget, creating a major sustainability issue (Oakley et al., 2012). The performance of WSP systems is affected by sludge accumulation (Verbyla et al., 2013a). Accordingly, it is necessary to understand the removal of pathogens for WSPs in which sludge has accumulated for years without removal.

The treated water from WSP systems is often used for irrigation. Although the social, economic, and environmental benefits of wastewater reuse have been well-documented (Cornejo et al., 2013; Mo and Zhang, 2012), a large portion of wastewater use for irrigation occurs in lowincome regions where wastewater treatment systems are overloaded, not well-maintained, or abandoned altogether. For example, nearly 2.4 billion $\mathrm{m}^{3}$ of treated wastewater are directly used for irrigation each year in North Africa and the Middle East (FAO, 2015), where many wastewater facilities are heavily overloaded (Ghneim, 2010; McIlwaine and Redwood, 2010). More land area in Latin America and the Caribbean is equipped for direct wastewater irrigation than in the Middle East and North Africa combined (FAO, 2015), but less than 10\% of the wastewater in this region receives adequate treatment, partially because of the large number of treatment plants that are experiencing operational problems, malfunctioning due to the lack of maintenance, or abandoned (CReW, 2014; Libhaber and Orozco-Jaramillo, 2012). The removal of fecal indicators and parasites in WSPs has been previously characterized (Ayres et al., 1992; von Sperling, 2005); however, while these models take into account pond size and hydraulic retention time (HRT), they may not necessarily account for the malfunction concerns resulting from a lack of maintenance in older WSP systems. The absence of maintenance for wastewater treatment systems thus creates uncertainty about the risks associated with wastewater use practices throughout the world. This is alarming, given that Target 6.3 of the Sustainable 
Development Goals is to substantially increase water recycling and reuse globally by 2030 (United Nations, 2015).

Further complicating this issue is the fact that little is known about pathogen fate and transport in these under-maintained wastewater treatment and unregulated wastewater use systems. Data about pathogens in water, soil, and crops from wastewater irrigation operations in developing countries are often not available because few laboratories in these regions are equipped to measure pathogens in environmental samples. The 2006 World Health Organization (WHO) guidelines (WHO, 2006) recommend the use of quantitative microbial risk assessment (QMRA) to develop safe water reuse policies. This requires measuring or assuming quantities of human pathogens in wastewater, and then assuming their fate and transport through treatment processes and into the irrigation fields and crops to which farmers and consumers are exposed. In previous QMRAs (e.g., Mok and Hamilton 2014; Shuval et al. 1997) and in an example from the 2006 WHO Guidelines for unrestricted water reuse for irrigation (WHO, 2006), quantities of pathogens on irrigated crops have been estimated by multiplying their concentration in water by the volume of water retained by a crop after irrigation. This approach may be flawed, since not all pathogens in this water necessarily remain on the crop, and some pathogens may remain from previous irrigation events. Concentrations of pathogens and fecal indicator organisms in irrigation water are seldom compared with their respective concentrations in irrigated soil and on irrigated crops.

The objective of this study was to assess the fate and concentrations of a broad range of human pathogens and fecal indicator organisms in water samples from WSP systems serving small cities $(<500,000$ residents $)$ and in soil and crop samples from fields irrigated with the effluent of those systems. The organisms chosen for this study were Escherichia coli, coliphage, Giardia, Cryptosporidium, and helminth eggs. The Cochabamba Valley was selected due to the fact that it was identified as the most representative region for wastewater use practices in Bolivia (GIZ, 2011); wastewater is used to irrigate more than 5,700 hectares of crops in this valley alone (Ministerio de Medio Ambiente y Agua, 2013). WSPs were chosen as the technology because they are among the most common wastewater treatment technologies used globally (Verbyla, 2015), especially when wastewater is used for irrigation. Results from a survey of 111 wastewater treatment systems in regions of Bolivia with water deficits revealed that approximately half of the systems were WSPs (Ministerio de Medio Ambiente y Agua, 
2013). After a preliminary survey of eight wastewater treatment plants in the Cochabamba Valley, two WSP systems serving the towns of Arani and Punata were selected as case examples for the study. These systems were selected because they both served small cities, had similar layouts, and had been in operation for at least 10 years. Also, farmers applied $100 \%$ of the effluent from both systems directly to fields during the dry season (which made sample collection feasible during several months throughout the year). The wastewater treatment plants in Arani and Punata are officially managed by municipal wastewater companies, but in practice they have not been well maintained and were largely abandoned at the time of the study. Sludge had not been removed from ponds in either system. This is common throughout Bolivia, where $37 \%$ of wastewater treatment systems are not functioning and many other systems perform poorly because of maintenance problems (Ministerio de Medio Ambiente y Agua, 2013); it is also common throughout the developing world (CReW, 2014; Libhaber and Orozco-Jaramillo, 2012; Patiño Gómez and Lara-Borrero, 2012). Because these WSP systems were undermaintained, it was hypothesized that the removal of the selected pathogens and fecal indicator organisms would be lower than rates previously reported (Ayres et al., 1992; von Sperling, 2005), leading to potentially higher densities in irrigated soil and on crops.

\section{Material and Methods}

\subsection{Waste Stabilization Pond and Irrigation Systems}

The wastewater treatment systems in Arani and Punata use a combination of anaerobic, facultative, and maturation ponds, some in series, some in parallel (Figure 1). The system in Arani, which received an average flow rate of approximately $750 \mathrm{~m}^{3} /$ day, contained two $425 \mathrm{~m}^{3}$ anaerobic ponds (in parallel), followed by two $1,500 \mathrm{~m}^{3}$ facultative ponds (in parallel), two 950 $\mathrm{m}^{3}$ primary maturation ponds (in parallel), and two $950 \mathrm{~m}^{3}$ secondary maturation ponds (in parallel). This system was constructed in 2000 and at the time of sampling, sludge had never been removed. The total theoretical HRT, based on the original pond volumes (not considering sludge accumulation) and the flow rate measured at the time of sampling, was 10 days. However, sludge had accumulated to the point where it blocked the entrance to many of the ponds, causing a situation where wastewater only flowed through one of each of the ponds in parallel. The sludge that had accumulated in the ponds receiving wastewater was estimated to occupy roughly $80 \%$ of the pond volumes. Also, wastewater was only flowing through one of each of the 
duplicate ponds in series, further reducing the effective volume by half. Considering the loss of volume due to sludge accumulation and uneven wastewater flow, the total theoretical HRT for this system at the time of sampling was probably closer to only one day (Iriarte et al., 2013; Mercado et al., 2013).

The WSP system in Punata received an average flow of $2,730 \mathrm{~m}^{3} /$ day, and consisted of three $1,300 \mathrm{~m}^{3}$ anaerobic ponds (in parallel), followed by two 7,000 $\mathrm{m}^{3}$ facultative ponds (in parallel), and three $3,000 \mathrm{~m}^{3}$ maturation ponds (in parallel). The total theoretical HRT, based on the original pond volumes (not considering sludge accumulation), and the flow rate measured at the time of sampling, was also 10 days. However, flow patterns had also been disturbed in this system, causing wastewater to only flow through one of each of the ponds in parallel. This unequal flow distribution may have occurred due to one or more of the following factors: 1) modifications were made to the final outlet channel to divert treated water to irrigation fields, which altered the level of water upstream in the ponds; 2) poor construction of the inspection boxes, causing unequal distribution of flow to ponds connected in parallel; or 3) the lack of maintenance, causing uneven sludge accumulation. Sludge in these ponds had not accumulated to the same extent as in the Arani system, but still had never been evacuated since construction in 1995. Considering the observed flow patterns and the estimated volume lost due to sludge accumulation, the theoretical HRT for this system at the time of sampling was estimated to be 2.5 days (Iriarte et al., 2013; Mercado et al., 2013). The final effluent from each system flowed to adjacent irrigation fields in open channels and was applied to crops using a border irrigation technique with small rectangular plots, known locally as melgas, platabandas, or cajetas. Water was applied by farmers to one end of the plot, and allowed to sequentially flood the furrows between each crop row until the entire zone was flooded.

\subsection{Sample Collection}

Grab samples were collected from the influent and effluent of the anaerobic ponds and from the final effluent from each system between $9 \mathrm{am}$ and $12 \mathrm{pm}$ in October and November of 2012 and in May, July, and October of 2013. A total of six to eight grab samples of untreated wastewater were analyzed for each of the microbiological parameters per system (Supplementary Material, Tables S1 and S2); four or five samples of treated wastewater were analyzed for each of the microbiological parameters (see Supplementary Material, Tables S5 and S6). A single sample was also collected in November 2012 from the extraction point of the irrigation channel 
in Punata. Samples of irrigated soil and crops were also collected in October 2012, November 2012, and July 2013. Generally, three to five samples were analyzed per microbiological parameter per site (see Supplementary Material, Tables S5 and S6). A larger number of soil samples from the Arani site $(\mathrm{n}=7)$ were analyzed for coliphage and helminth eggs, but a smaller number of samples were analyzed for Giardia and Cryptosporidium from the Arani crops ( $\mathrm{n}=1)$, the Punata soil ( $\mathrm{n}=2)$, and the Punata crops (no samples analyzed). Different quantities of crop and soil samples were analyzed per microbiological parameter per site due to limited access to the site during irrigation season and the limited availability of crops that could be harvested at the particular time of the site visit. Alfalfa was the only crop harvested from the Arani system irrigation field. Chard, beet greens, quinoa, and fava beans were harvested from the Punata system irrigation field. Plants were aseptically clipped at the root stem and placed in sterile containers on ice.

Samples were processed and analyzed within 48 hours at the Centro de Aguas y Saneamiento Ambiental (CASA), Universidad Mayor de San Simon (UMSS), in Cochabamba. Water, soil, and crop samples were analyzed for coliforms, coliphages, Giardia cysts, Cryptosporidium oocysts, and helminth eggs, using the methods described below. Water samples from the WSP systems in Arani ( $n=3)$ and Punata ( $n=5)$ were also analyzed for the following physical-chemical parameters using Standard Methods (APHA et al., 2012): total suspended solids (TSS), five-day biochemical oxygen demand $\left(\mathrm{BOD}_{5}\right)$, chemical oxygen demand (COD), total phosphorus (TP), and ammonia nitrogen $\left(\mathrm{NH}_{3}-\mathrm{N}\right)$.

\subsection{Enumeration of Coliforms}

The concentration of $E$. coli in water samples was determined using membrane filtration (US EPA, 2006). Water samples or dilutions of $100 \mathrm{~mL}$ were passed through a $47-\mathrm{mm}$ diameter filter with a pore size of $0.45 \mu \mathrm{m}$, and the filter was placed on a plate with modified mTEC agar, incubated at $35^{\circ} \mathrm{C}$ for 2 hours, and then at $44.5^{\circ} \mathrm{C}$ for 22 hours. A direct count plating method with MacConkey agar (BD Difco) was used to determine the concentration of lactose-fermenting bacterial colonies in soil and crop samples. For soil samples, $25 \mathrm{~g}$ of soil were diluted in $225 \mathrm{~mL}$ sterile DI water (for a final volume of $250 \mathrm{~mL}$ ), which was agitated manually by shaking for one minute. For crop samples, $25 \mathrm{~g}$ of the crop were added to $225 \mathrm{~mL}$ of sterile DI water (for a final volume of $250 \mathrm{~mL}$ ) and blended in a food blender. Then, $0.2 \mathrm{~mL}$ of diluted soil or crop sample were poured onto a plate with MacConkey agar. After an incubation period of 24 hours at $37^{\circ} \mathrm{C}$, 
only red- or magenta-colored bacteria colonies with a halo of precipitate were counted. No further confirmation tests were performed, therefore the bacterial densities reported for soil and crop samples represent lactose-fermenting Gram-negative bacteria (indicative of coliforms). All samples (water, soil, and crop) were analyzed in duplicate and the average number of colonies was recorded and used to estimate the concentrations.

\subsection{Enumeration of Coliphage}

The concentration of coliphages was determined using a single agar layer method (APHA et al. 2012; US EPA 2001) with modifications as described by Grabow and Coubrough (1986) with host E. coli strain C-3000 (ATCC \#15597, Manassas, VA, USA). For water samples, $5 \mathrm{~mL}$ of sample or sample dilutions were analyzed in duplicate. Plates were incubated overnight (8 12 hours) at $35^{\circ} \mathrm{C}$, and plaques forming on the lawn of the host bacteria were enumerated. The average number of plaques from duplicate samples was recorded and used to estimate the concentration. Soil and crop samples for coliphage enumeration were concentrated in the same manner as described above for coliforms, using the same dilutions, except that a volume of $5 \mathrm{~mL}$ of samples (or sample dilutions) was analyzed for coliphage samples.

\subsection{Enumeration of Protozoan Parasites}

Samples were analyzed for Giardia cysts and Cryptosporidium oocysts, using US EPA Method 1623 (US EPA, 2005) with some modifications. For water samples, a sample volume of 5 to $10 \mathrm{~L}$ was concentrated to a volume of $10 \mathrm{~mL}$ using centrifugation at $1,100 \times \mathrm{g}$ for $15 \mathrm{~min}$. For soil samples, $25 \mathrm{~g}$ were added to a flask with $100 \mathrm{~mL}$ of Tris-Tween buffer solution (50 mM Tris with $0.5 \% \mathrm{v} / \mathrm{v}$ Tween 80 ), and mixed for $15 \mathrm{~min}$ with a magnetic stir bar. The samples were then filtered using Whatman Grade 1 filter paper (Sigma Aldrich) with a filter funnel, a Buchner flask, and a vacuum pump. The filter was then washed three times with an additional $200 \mathrm{~mL}$ of Tris-Tween buffer. Next, the samples were placed in $50-\mathrm{mL}$ tubes and centrifuged at $1,100 \times g$ for $15 \mathrm{~min}$, as was done for the water samples, to concentrate to a final volume of $10 \mathrm{~mL}$. For crop samples, $200 \mathrm{~mL}$ of Tris-Tween buffer were added to a stainless steel blender with $25 \mathrm{~g}$ of the edible portion of the crop, and the mixture was blended at the low setting for 2 minutes. Then, the mixture was filtered over a stainless steel sieve with $150-\mu \mathrm{m}$ pore size. An additional $200 \mathrm{~mL}$ of Tris-Tween buffer were washed over the sieve. The resulting filtrate was then distributed into $50-\mathrm{mL}$ tubes and centrifuged at $1,100 \times \mathrm{g}$ for $15 \mathrm{~min}$ to concentrate to a final volume of $10 \mathrm{~mL}$. 
Cysts and oocysts in the concentrated $10-\mathrm{mL}$ volumes from water, soil, and crop samples were further concentrated using immune-magnetic separation with the Applied Biosystems Dynabeads ${ }^{\circledR}$ G-C Combo Kit (IDEXX Laboratories, Inc., Maine, USA), in accordance with the manufacturer's instructions. Following this process, $50 \mu \mathrm{L}$ of the concentrated cysts and oocysts were transferred to microscope slides, left overnight at room temperature to dry, and then stained using the Merifluor ${ }^{\circledR}$ Cryptosporidium/Giardia kit (Fisher Scientific, Pennsylvania, USA). Finally, cysts and oocysts were visualized under a microscope with an epi-fluorescence set (Eclipse E600, Nikon), and enumerated based on their color under fluorescence (apple green) and the morphologies.

\subsection{Enumeration of Helminth Eggs}

The concentration of helminth eggs in water samples was determined using CASA's standard protocol which has been described previously (Verbyla, 2012). Briefly, eggs were isolated from samples using sedimentation, flotation with magnesium sulfate, and biphasic separation using an ether-ethyl and sulfuric acid solution. Portions of the concentrated samples were added to Neubauer Improved Bright-Line counting chambers, which were examined under a microscope (Eclipse E600, Nikon) at $400 \times$ or 1,000× magnification, and helminth eggs were identified and enumerated. For soil samples, helminth eggs were concentrated using the Tulane method, which has a rate of recovery of $75.5 \%$ with a precision (percent variation) of $32.5 \%$ for soil samples (Bowman et al., 2003). Briefly, $20 \mathrm{~g}$ of soil were mixed with $200 \mathrm{~mL}$ of sterile DI water and transferred to a stainless steel blender where it was agitated for one min. The mixture was then transferred to a beaker and allowed to settle overnight (12 to $14 \mathrm{~h}$ ), after which the supernatant was discarded, leaving the bottom $100 \mathrm{~mL}$. The blending/settling process was then repeated. Each time samples were transferred, the sides and bottom of the containers were washed with sterile DI water at least twice, to recover any helminth eggs that may have attached to the containers. After this second round of blending/settling, $900 \mathrm{~mL}$ of $7 \times$ detergent solution (5\%) (MP Biomedicals) was added to the sediment; the solution was mixed, allowed to settle for two hours, and then the top $90 \%$ was decanted. $300 \mathrm{~mL}$ of detergent solution was then added and mixed for five minutes. The entire mixture was passed through a \#20 mesh sieve, then through a \#50 mesh sieve. The tops of the sieves were brushed lightly with a hair brush and sprayed with sterile DI water to help separate any remaining eggs from soil particles retained on the sieves. All filtrate was collected in a large beaker in the bottom of the sieves. Once more, $900 \mathrm{~mL}$ of $7 \times$ 
detergent solution (5\%) was added, mixed, and the samples were allowed to settle for 2 hours. After this, the supernatant was decanted, leaving only the bottom $10 \%$ of the sample which was mixed and distributed into 50-mL centrifuge tubes. The contents of these tubes was then treated as water samples and analyzed as described above. Edible portions of crop samples were aseptically placed into sterile containers with Tris-Tween buffer, manually agitated for 5 minutes, and then the buffer was transferred to a beaker. This washing process was performed three times for each sample, using a total buffer volume of $1-2 \mathrm{~L}$, composited into a single beaker for each sample. The washing buffer was then processed like the water samples.

\subsection{Statistical Analyses}

A probability plot correlation coefficient test (NIST/SEMATECH, 2012) was used to assess the conformity of concentrations in the wastewater to the lognormal distribution. The data sets for some of the samples were left-censored (the measured concentration in some sample replicates was below the method limit of detection). Therefore, summary statistics and interval estimates were computed with the 'robust' implementation of regression on order (ROS) statistics, which uses a least-squares regression on a probability plot of the data, assuming a lognormal distribution to impute values for the censored portion, and is recommended for small sample sizes (Helsel, 2012). For samples where microorganisms were only detected in one replicate, the most probable number equation (Jarvis et al., 2010) was used to estimate the concentration. Two way analysis of variance (ANOVA) was used to assess variability in the densities and removal of microorganisms with respect to the time of day and month of sampling, using the $\log _{10}$-transformed concentrations or the $\log _{10}$ removals as the dependent continuous variable. The microorganism type and the time of sample (either month of the year or morning vs. afternoon) were used as the independent categorical variables. After an analysis of the residuals indicated potential deviations from normality, a Friedman test was used to assess seasonal variability, with blocking by microorganism type. A two-sample Wilcoxon rank sum test was used to test if the $\log _{10}$-transformed concentrations of microorganisms detected at two sample points were significantly different. A significance level of 0.05 was used for all statistical analyses. Wilcoxon shifts were also assessed at the 0.01 and 0.10 levels. Calculations were performed using 'R' version 3.2.2 (The R-Project for Statistical Computing, Vienna, Austria) with the 'non-detects and data analysis' (NADA) package (Lee, 2013). 


\section{Results and Discussion}

\subsection{Physical-Chemical Quality of Reclaimed Water}

The pond systems in Arani and Punata provided reductions of $74 \%$ and $86 \%$ for TSS, $69 \%$ and $54 \%$ for $\mathrm{BOD}_{5}$, and $71 \%$ and $55 \%$ for $\mathrm{COD}$, respectively. This treatment performance is lower than expected for WSP systems with similar size and flow rate (Mara, 2003). Interestingly, the passage of wastewater through $200 \mathrm{~m}$ of an open irrigation channel in Punata, from the pond system outlet to the location where water is extracted for irrigation, resulted in additional reductions of $58 \%, 77 \%$, and $25 \%$, for $\mathrm{TSS}, \mathrm{BOD}_{5}$, and $\mathrm{COD}$, respectively. This demonstrates that additional treatment is achieved between the wastewater treatment plant and the irrigation fields. The concentration of $\mathrm{NH}_{3}-\mathrm{N}$ in the effluent of both systems was $>75 \mathrm{mg} \mathrm{L}^{-1}$, which is well above most criteria for acute or chronic toxicity for aquatic organisms (National Research Council, 2012). The concentration of total phosphorus was $>15 \mathrm{mg} \mathrm{L}^{-1}$ in both systems. The nutrient levels in the treated effluent indicate the environmental benefits of land applying treated wastewater instead of discharging to surface water bodies (Cornejo et al., 2013; Verbyla et al., 2013b).

\subsection{Removal of Pathogens and Indicators in Stabilization Ponds}

The data for concentrations of pathogens and fecal indicators in untreated wastewater generally did not have significant deviations from the lognormal distribution (see Supplementary Material, Tables S1 and S2), which supported the use of the robust ROS methods to handle censored data. The concentrations of the selected microorganisms in the untreated wastewater appeared to have minor seasonal variations, with higher concentrations in November than other months (Supplementary Material, Figure S1). Additionally, the concentrations of parasites (but not fecal indicators) appeared to have minor diurnal variations, with slightly higher concentrations measured during the late morning hours (Supplementary Material, Figure S2). However, none of these variations were statistically significant. The $\log _{10}$ differences in the concentrations of E. coli, coliphage, Giardia cysts, Cryptosporidium oocysts, and helminth eggs between the overall influent and effluent points for the two WSP systems are provided in Table 1. With the exception of coliphage in the Arani WSP system, the $\log _{10}$ removals of all microorganisms were statistically significant at the $\alpha=0.10$ level. Other than Giardia, for which there was significantly greater $\log _{10}$ removal in the Arani system than the Punata system (p-value 
$=0.02$ ), there were no statistically significant differences in the $\log _{10}$ removal of pathogens or fecal indicators between the two systems.

For both stabilization pond systems, the concentrations of E. coli in the final treated wastewater are two orders of magnitude above the limit for thermotolerant coliforms that was recommended in the 1989 WHO guidelines (WHO 1989) for wastewater reuse in agriculture $(<1,000 \mathrm{MPN} / 100 \mathrm{~mL})$. The average E. coli removal in the Arani and Punata systems was 1.0and $0.8-\log _{10}$ units, respectively. This observed removal efficiency is similar to E. coli removal reported for free water surface flow constructed wetlands with similar overall HRTs (Wu et al., 2016). It is also similar to the removal predicted using von Sperling's $(1999 ; 2003 ; 2005)$ dispersed flow model, which uses the ratio of pond width to pond length as an estimate of the dispersion number. Assuming the same decay rates, but reduced pond volumes (to account for observed sludge accumulation), von Sperling's (1999; 2003; 2005) dispersed flow model underpredicts the E. coli removals observed in the Arani and Punata WSP systems (see Supplementary Material). However, decay rates should increase with shallower depths, which may be one explanation for the results observed in these two overloaded systems. If pond volume and depth reduction because of sludge accumulation are taken into consideration to estimate new decay rates, the model over-predicts the observed E. coli removals.

Coliphage removal in both WSP systems was less than or equal to $1-\log _{10}$ unit and was only significant in the Punata system $(\alpha=0.05)$. This was expected given the low HRT in the Arani system, and since results from a recent review of virus and bacteriophage removal in pond systems (Verbyla and Mihelcic, 2015), which indicated that pond systems require 14.5 to 20.9 days of retention on average to achieve each $\log _{10}$ removal of viruses or bacteriophage. The observed removals of protozoan parasites Giardia and Cryptosporidium in the Arani and Punata systems were similar to values reported by others in a previous study (Reinoso et al., 2011). Eggs from a wide variety of helminth genera were detected in the water samples from the Arani and Punata systems, including Ascaris spp. (41\%), Hymenolepis spp. (27\%), Taenia spp. (19\%), Fasciola spp. (10\%), and Trichuris spp. (3\%); relative frequencies which are similar to those reported in septage sludge from Cần Thơ, Vietnam (Yen-Phi et al., 2010). The helminth egg concentrations calculated for treated wastewater samples were between 31 and 130 eggs L $^{-1}$ for

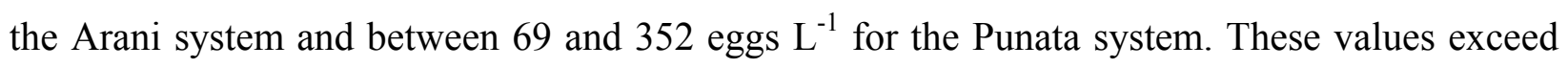
the maximum concentration of 1 egg $\mathrm{L}^{-1}$ recommended by the WHO (2006) and greatly exceed 
the limit of 0.1 eggs $\mathrm{L}^{-1}$ if children are present. The observed removals of helminth eggs in the Arani and Punata WSP systems were also low compared to the removal predicted by a design equation for helminth egg removal in WSP systems (Ayres et al., 1992). This design equation is referenced in the most current version of the WHO Guidelines for Wastewater Use in Agriculture (WHO, 2006), however several other researchers have also found that this design equation under-predicts helminth egg removal in some WSPs. For instance, helminth eggs were only removed by $92 \%$ in a facultative pond with an HRT of 76 days (Reinoso et al., 2008); 45 eggs/L were detected in a WSP system in Bolivia with three ponds in series and an overall HRT of 27 days (Verbyla et al., 2013a); more than 100 eggs/L were detected in the effluent of a WSP system with 20 days HRT (Ben Ayed et al., 2009). According to the Ayres et al. (1992) design equation, a WSP with 20 days HRT should remove $>99.99 \%$ of helminth eggs $(>4 \log )$.

If the ponds were operating with their full volumes (i.e., zero sludge accumulation), then the Arani and Punata WSP systems should provide at least 3.6- and 3.1- $\log _{10}$ removal of helminth eggs, respectively, according to the lower $95 \%$ confidence interval of the model proposed by Ayres et al. (1992) (see Supplementary Material). In addition, even when accounting for the reduced HRT because of sludge accumulation (i.e., assuming 0.9 days overall HRT for the Arani system and 2.5 days overall HRT for the Punata system), the Ayres et al. (1992) model still predicts at least a $1.7-\log _{10}$ removal of helminth eggs for both systems. The observed helminth egg removals in the Arani and Punata systems were more than an order of magnitude lower than these predicted values. The likely explanation for the poor efficiency of helminth egg removal is the excessive sludge accumulation, which can affect pond hydraulics, creating short-circuits that may be capable of carrying helminth eggs through to the outlet, or resuspending eggs that have been deposited in the pond sediments (Verbyla et al., 2013a). This is an indication that the existing helminth egg removal model for WSP systems may not be appropriate for systems with accumulated sludge.

\subsection{Fate of Pathogens and Indicators in Irrigation Systems}

The quantiles of the concentrations of microorganisms detected at each point in the two pond systems and in samples of soil and crops irrigated with treated wastewater are presented in Figure 2 (the data used to calculate mean, median and ranges are presented as Supplementary Material, Tables S5 and S6). In the Punata system, the passage of water through the irrigation channels did not appear to result in any additional removal of the selected microorganisms. The 
concentrations of the selected microorganisms in soil and on crops are essentially the same in both systems with the following exceptions: coliforms were only detected in samples of beet greens and chard in Punata and coliphages were only detected on fava beans in Punata.

To assess the transfer of the selected pathogens and fecal indicators from irrigation water to soil and crops, ratios of their concentrations in soil or crop samples divided by their respective concentrations in irrigation water (termed crop-water and soil-water ratios, with units of $\mathrm{mL} \mathrm{g}^{-1}$ ) were calculated, using quantiles of the ROS concentration estimates to incorporate variability and uncertainty (Figure 3). A higher ratio equates to a higher concentration in soil or crops relative to irrigation water. This can indicate more efficient transfer from irrigation water to soil or crops, longer survival in soil or on crops, or slower leaching or washing away from soil or crops. The ratios for coliphage were the lowest (generally $<0.1 \mathrm{~mL} \mathrm{~g}^{-1}$ ); the ratios for Giardia and Cryptosporidium were similar to each other (generally between 1 and $100 \mathrm{~mL} \mathrm{~g}^{-1}$ ) but were higher than the ratios for coliphage; and the ratios for helminth eggs were the highest of all (generally between 100 and $1,000 \mathrm{~mL} \mathrm{~g}^{-1}$ ). The coliphage crop-water ratios were similar to findings reported by Mok and Hamilton (2014) regarding the volume of water captured by irrigated chard, cabbage, broccoli and lettuce, which were used to estimate pathogen dose and microbial risk. The crop-water ratios for helminth eggs, Giardia, and Cryptosporidium were generally orders of magnitude greater. It is important to note that the higher ratios for parasites may be a result of the methods used to detect these organisms. Eggs and (oo)cysts were quantified by microscope examination based on morphology without distinguishing viability, while the assay used to quantify coliphages in water, soil, and crop samples measured the formation of plaques on the bacterial host strain E. coli C-3000 (which can only be accomplished by viable coliphages). Thus the lower coliphage ratios may reflect their decay in soil or on crops, since samples were generally collected several days after an irrigation event. Because the ratios calculated for Giardia cysts, Cryptosporidium oocysts, and helminth eggs do not account for this loss of viability, they may not over-estimate the concentration of viable (oo)cysts and eggs in soil and on crops by very much. Helminth eggs, Giardia cysts, and Cryptosporidium oocysts can persist for several months in soil (up to several years for Ascaris) and several weeks on crops; this is longer than the persistence of some excreted enteric viruses (e.g., enterovirus, poliovirus), which are inactivated within a few weeks in soil and within only a few days on crops (Feachem et al., 1983; Mara and Feachem, 1999). Helminth eggs also accumulate in sludge (Nelson, 2003; 
Yen-Phi et al., 2010), meaning that the crop-water and soil-water ratios of helminth eggs and (oo)cysts theoretically should be greater than the corresponding ratios for coliphage.

From a policy development standpoint, these ratios could be used to estimate concentrations of pathogens in soil or on crops relative to a known or proposed maximum concentration in irrigation water (when border or furrow irrigation practices are used), to evaluate risks associated with irrigation water quality standards. To be conservative, the upper $95^{\text {th }}$ percentile value of the estimated ratio should be used. For example, for a treatment system that complies with the $2006 \mathrm{WHO}$ Guidelines recommendation of $<1 \mathrm{egg} \mathrm{L}^{-1}$ in irrigation water, given an estimated crop-water ratio of $630 \mathrm{~mL} \mathrm{~g}^{-1}$ for helminth eggs (the $95^{\text {th }}$ percentile of the ratio for the Punata system, see Supplementary Material), the corresponding concentration of helminth eggs in the irrigated crop should be $<0.63$ eggs g $^{-1}$, which would correspond with a dose of $<63$ eggs if $100 \mathrm{~g}$ of raw produce were ingested by a consumer. To put this into perspective, the median infective dose of Ascaris eggs for communities in Mexico has been estimated to be between 35 and 859 eggs (Navarro et al., 2009).

\section{Conclusions}

The use of WSPs and other wastewater treatment processes that are simple to operate enhances the technical and operational sustainability of wastewater treatment operations in developing countries (Libhaber and Orozco-Jaramillo, 2012). Thus, the poor performance of the systems reported here does not imply that WSP systems should not be used. Rather, the results of this study demonstrate the importance of maintenance, in particular of incorporating amortized capital maintenance costs into annual operating and maintenance budgets to plan for large maintenance tasks such as sludge removal. Furthermore, the inclusion of a wider variety of local stakeholders in operation, maintenance, and decision-making processes associated with wastewater management can help achieve long-term adoption and sustainability of resource recovery (Guest et al., 2009; Huibers et al., 2010; Wells et al., 2016). Despite the issues associated with the performance of the wastewater treatment systems from this study, farmers from local cooperatives still value the partially-treated effluent and use it for irrigation. Many of them also help maintain the grounds at the wastewater treatment plants in Arani and Punata. Collaborative efforts between municipal authorities and farmers have been previously described as a potentially mutualistic and beneficial arrangement for managing wastewater in small 
communities (Oron et al., 1999). However, local farmers are not often trained with the technical skills related to wastewater management and safe reuse practices. The inclusion of farmers in the planning process for wastewater treatment and reuse may be one solution to help improve the long-term performance of WSP systems and insure safe water reuse, which is one of the targets of the post-2015 Sustainable Development Goals (United Nations, 2015). However, for this approach to be successful, farmers should be integrated into training programs that are normally targeted toward municipal wastewater authorities, so that their efforts can contribute to the successful operation, maintenance, and long-term sustainability of wastewater treatment and resource recovery.

\section{Acknowledgements}

This article is derived from work that was funded in part by the U.S. Agency for International Development (USAID) through the U.S. National Academy of Sciences (NAS) as part of the Partnerships for Enhanced Engagement in Research (PEER) Science program, under Sub-Grant No. PGA-2000001988. Any opinions, findings, conclusions, or recommendations expressed are those of the authors alone, and do not necessarily reflect the views of USAID or NAS. This material is also based upon work supported by the U.S. National Science Foundation under Grant Nos. 0966410 and 1243510 and the Graduate Research Fellowship Program under Grant No. 1144244. The funding organizations did not play a role in the collection, analysis and interpretation of data, the writing of the report, or the decision to submit the article for publication. Sarina Ergas, Jody Harwood, Mya Breitbart, and Norma Alcantar are acknowledged for feedback on the manuscript and Gloria Fuentes and Juan Pablo Rocha are acknowledged for their support in the laboratory.

\section{References}

APHA, AWWA, WEF, 2012. Standard Methods for the Examination of Water and Wastewater, 22nd Ed. American Public Health Association, American Water Works Association, Water Environment Federation, Baltimore, Maryland.

Ayres, R.M., Alabaster, G.P., Mara, D.D., Lee, D.L., 1992. A Design Equation for Human Intestinal Nematode Egg Removal in Waste Stabilization Ponds. Water Res. 26, 863-865. 
Ben Ayed, L., Schijven, J., Alouini, Z., Jemli, M., Sabbahi, S., 2009. Presence of parasitic protozoa and helminth in sewage and efficiency of sewage treatment in Tunisia. Parasitol. Res. 105, 393-406.

Bowman, D.D., Little, M.D., Reimers, R.S., 2003. Precision and Accuracy of an Assay for Detecting Ascaris Eggs in Various Biosolid Matrices. Water Res. 37, 2063-2072.

Cornejo, P.K., Zhang, Q., Mihelcic, J.R., 2013. Quantifying benefits of resource recovery from sanitation provision in a developing world setting. J. Environ. Manage. 131, 7-15.

CReW, 2014. Review of the Access to, Availability of, and Organizational Readiness for Uptake of Funding for the Wastewater Sector in Selected Participating Countries. Washington, D.C., USA.

FAO, 2015. AQUASTAT database. Food and Agricultural Organization, United Nations. http://www.fao.org/nr/water/aquastat/main/index.stm (Accessed 09/01/15)

Feachem, R.G., Bradley, D.J., Garelick, H., Mara, D.D., 1983. Sanitation and Disease: Health Aspects of Excreta and Wastewater Management. John Wiley \& Sons, Chichester, England.

Ghneim, A., 2010. Wastewater Reuse and Management in the Middle East and North Africa: A Case Study of Jordan. PhD Dissertation, Department of Environmental and Land Economics, Technical University of Berlin.

Grabow, W.K., Coubrough, P., 1986. Practical Direct Plaque Assay for Coliphages in 100-ml Samples of Drinking Water. Appl. Environ. Microbiol. 52, 430-433.

Guest, J.S., Skerlos, S.J., Barnard, J.L., Beck, M.B., Daigger, G.T., Hilger, H., Jackson, S.J., Karvazy, K., Kelly, L., MacPherson, L., Mihelcic, J.R., Pramanik, A., Raskin, L., van Loosdrecht, M.C.M., Yeh, D., Love, N.G., 2009. A New Planning and Design Paradigm to Achieve Sustainable Resource Recovery from Wastewater. Environ. Sci. Technol. 43, 6126-6130.

Helsel, D.R., 2012. Computing Summary Statistics and Totals, in: Statistics for Censored Environmental Data Using Minitab and R. John Wiley \& Sons, Hoboken, New Jersey, USA, pp. 62-98.

Huibers, F.P., Redwood, M., Rashid-Sally, L., 2010. Challenging Conventional Approaches to Managing Wastewater Use in Agriculture, in: Drechsel, P., Scott, C., Raschid-Sally, L., Redwood, M., Bahri, A. (Eds.), Wastewater Irrigation and Health: Assessing and Mitigating Risk in Low-Income Countries. Earthscan, London, UK; Sterling, Virginia.

Iriarte, M., Mercado, A., Verbyla, M.E., Fuentes, G., Rocha, J.P., Almanza, M., 2013. Monitoreo de microorganismos indicadores y patógenos en dos sistemas de lagunas de estabilización en el Valle Alto de Cochabamba (Monitoring indicators and pathogenic microorganisms in two stabilization pond systems in the high valley of Cochabamba), in: XV Congreso 
Bolivariano de Ingenieria Sanitaria y Medio Ambiente, November 20-22, 2013. AIDIS, Cochabamba, Bolivia. Available online: http://usf-reclaim.org/xv_congreso_bolivariano/

Jarvis, B., Wilrich, C., Wilrich, P.-T., 2010. Reconsideration of the derivation of Most Probable Numbers, their standard deviations, confidence bounds and rarity values. J. Appl. Microbiol. $109,1660-1667$.

Lee, L., 2013. Package NADA. v1.5-6 http://cran.r-project.org/web/packages/NADA/NADA.pdf (Accessed 09/01/15).

Libhaber, M., Orozco-Jaramillo, Á., 2012. Sustainable Treatment and Reuse of Municipal Wastewater: For Decision Makers and Practicing Engineers. IWA Publishing, London, UK.

Mara, D.D., 2003. Domestic wastewater treatment in developing countries, 1st ed. ed. Earthscan/James \& James, London, UK.

Mara, D.D., Feachem, R.G.A., 1999. Water- and excreta-related diseases: Unitary environmental classification. J. Environ. Eng. 125, 334-339.

Mcllwaine, S., Redwood, M. (Eds.), 2010. Greywater use in the Middle East: Technical, Social, Economic and Policy Issues. Practical Action Publishing, Ottawa, Canada.

Mercado, A., Coronado, O., Iriarte, M., 2013. Evaluación de la eficiencia la planta de tratamiento de aguas residuales de Punata, Cochabamba, Bolivia. Importancia de la operación y mantenimiento (Evaluation of the efficiency of a wastewater treatment plant in Punata, Cochabamba, Bolivia: Importance of operation and maintenance), in: XV Congreso Bolivariano de Ingenieria Sanitaria y Medio Ambiente, November 20-22, 2013. AIDIS, Cochabamba, Bolivia. Available online: http://usf-reclaim.org/xv_congreso_bolivariano/

Ministerio de Medio Ambiente y Agua, 2013. Sistematización sobre tratamiento y reúso de aguas residuales (Systematization of wastewater treatment and reuse). La Paz, Bolivia.

Mo, W., Zhang, Q., 2012. Can municipal wastewater treatment systems be carbon neutral? J. Environ. Manage. 112, 360-367.

Mok, H.-F., Hamilton, A.J., 2014. Exposure Factors for Wastewater-Irrigated Asian Vegetables and a Probabilistic Rotavirus Disease Burden Model for Their Consumption. Risk Anal. 34, 602-613.

National Research Council, 2012. Water Reuse: Potential for Expanding the Nation's Water Supply Through Reuse of Municipal Wastewater. Washington, D.C.

Navarro, I., Jiménez, B., Lucario, S., Cifuentes, E., 2009. Application of Helminth ova infection dose curve to estimate the risks associated with biosolid application on soil. J. Water Health 7, 31-44. 
Nelson, K.L., 2003. Concentrations and inactivation of Ascaris eggs and pathogen indicator organisms in wastewater stabilization pond sludge. Water Sci. Technol. 48, 89-95.

NIST/SEMATECH, 2012. e-Handbook of Statistical Methods. http://www.itl.nist.gov/div898/ handbook/ (Accessed 09/01/15).

Oakley, S.M., Mendonça, L.C., Mendonça, S.R., 2012. Sludge removal from primary wastewater stabilization ponds with excessive accumulation: a sustainable method for developing regions. J. Water, Sanit. Hyg. Dev. 2, 68-78.

Oron, G., Campos, C., Gillerman, L., Salgot, M., 1999. Wastewater treatment, renovation and reuse for agricultural irrigation in small communities. Agric. Water Manag. 38, 223-234.

Patiño Gómez, J.M., Lara-Borrero, J.A., 2012. Investment, operation and maintenance costs (2012) for natural wastewater treatment systems in small communities in Colombia. Eur. Water 40, 19-30.

Reinoso, R., Torres, L.A., Bécares, E., 2008. Efficiency of natural systems for removal of bacteria and pathogenic parasites from wastewater. Sci. Total Environ. 395, 80-6.

Reinoso, R., Blanco, S., Torres-Villamizar, L.A., Bécares, E., 2011. Mechanisms for parasites removal in a waste stabilisation pond. Microb. Ecol. 61, 684-92.

Shuval, H.I., Lampert, Y., Fattal, B., 1997. Development of a risk assessment approach for evaluating wastewater reuse standards for agriculture. Water Sci. Technol. 35, 15-20.

United Nations, 2015. Resolution adopted by the General Assembly. New York, NY, USA.

US EPA, 2001. Method 1602: Male-specific ( $\mathrm{F}+$ ) and Somatic Coliphage in Water by Single Agar Layer (SAL) Procedure. EPA 821-R-01-029, Washington, D.C.

US EPA, 2005. Method 1623: Cryptosporidium and Giardia in Water by Filtration/IMS/FA. EPA 815-R-05-002, Cincinnati, Ohio.

US EPA, 2006. Method 1603: Escherichia coli (E. coli) in Water by Membrane Filtration Using Modified Membrane-Thermotolerant Escherichia coli Agar (Modified mTEC). Washington, D.C.

Verbyla, M.E., 2012. Assessing the Reuse Potential of Wastewater for Irrigation: The Removal of Helminth Eggs from a UASB Reactor and Stabilization Ponds in Bolivia. Master of Science Thesis, Department of Civil and Environmental Engineering, University of South Florida. http://scholarcommons.usf.edu/etd/4414 (Accessed 11/20/15).

Verbyla, M.E., Oakley, S.M., Lizima, L.A., Zhang, J., Iriarte, M., Tejada-Martinez, A.E., Mihelcic, J.R., 2013a. Taenia eggs in a stabilization pond system with poor hydraulics: concern for human cysticercosis? Water Sci. Technol. 68, 2698-2703. 
Verbyla, M.E., Oakley, S.M., Mihelcic, J.R., 2013b Wastewater Infrastructure for Small Cities in an Urbanizing World: Integrating Protection of Human Health and the Environment with Resource Recovery and Food Security. Environ. Sci. Technol. 47, 3598-3605.

Verbyla, M.E., Mihelcic, J.R., 2015. A review of virus removal in wastewater treatment pond systems. Water Res. 71, 107-124.

von Sperling, M., 2005. Modelling of coliform removal in 186 facultative and maturation ponds around the world. Water Res. 39, 5261-73.

von Sperling, M., 2003. Influence of the dispersion number on the estimation of coliform removal in ponds. Water Sci. Technol. 48, 181-8.

von Sperling, M., 1999. Performance evaluation and mathematical modelling of coliform die-off in tropical and subtropical waste stabilization ponds. Water Res. 33, 1435-1448.

Wells, E.C., Zarger, R.K., Whiteford, L.M., Mihelcic, J.R., Koenig, E.S., Cairns, M.R., 2014. The impacts of tourism development on perceptions and practices of sustainable wastewater management on the Placencia Peninsula, Belize. J. Clean. Prod. (in press, corrected proof), doi:10.1016/j.jclepro.2014.08.050.

WHO, 2006. Volume II of the Guidelines for the safe use of wastewater, excreta and greywater: Wastewater use in agriculture. France.

WHO, 1989. Health guidelines for the use of wastewater in agriculture and aquaculture. Geneva, Switzerland.

Wu, S., Carvalho, P.N., Müller, J.A., Manoj, V.R., Dong, R., 2016. Sanitation in constructed wetlands: A review on the removal of human pathogens and fecal indicators. Sci. Total Environ. 541, 8-22.

Yen-Phi, V.T., Rechenburg, A., Vinneras, B., Clemens, J., Kistemann, T., 2010. Pathogens in septage in Vietnam. Sci. Total Environ. 408, 2050-2053. 


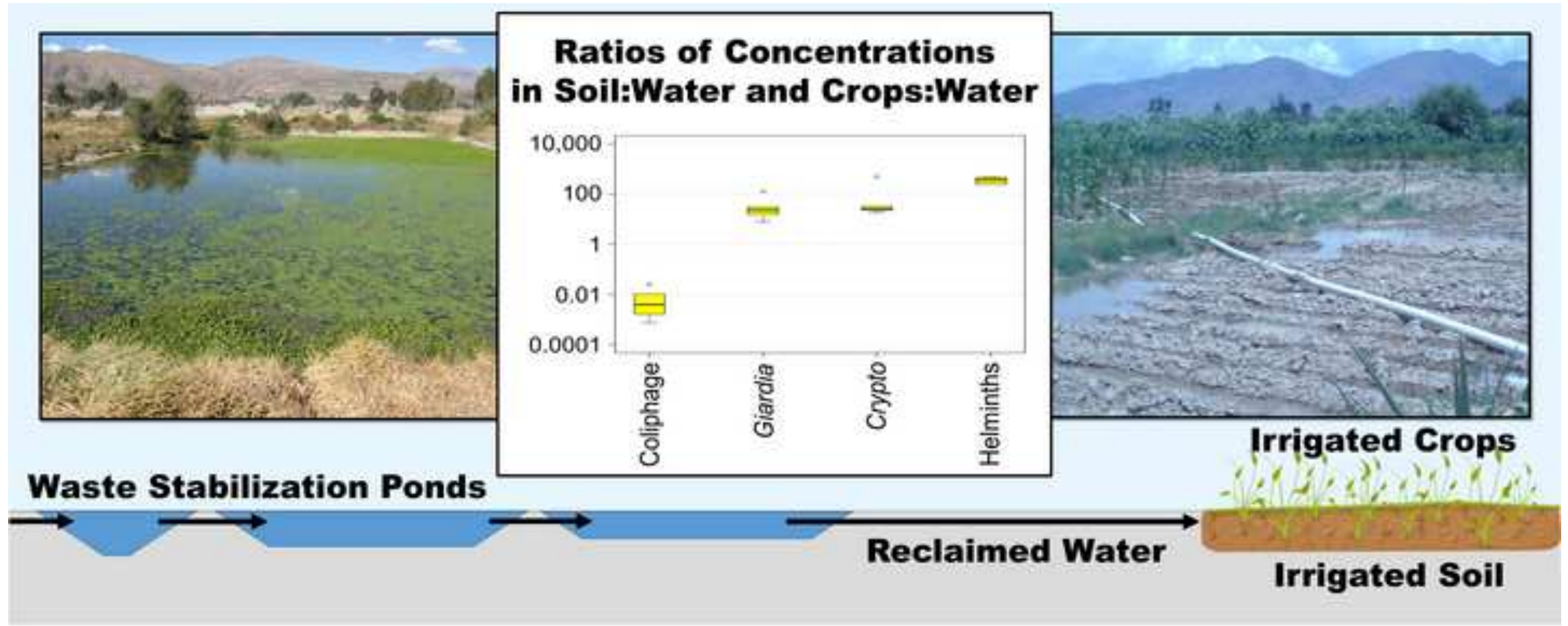


(a)

Facultative Ponds Maturation Ponds

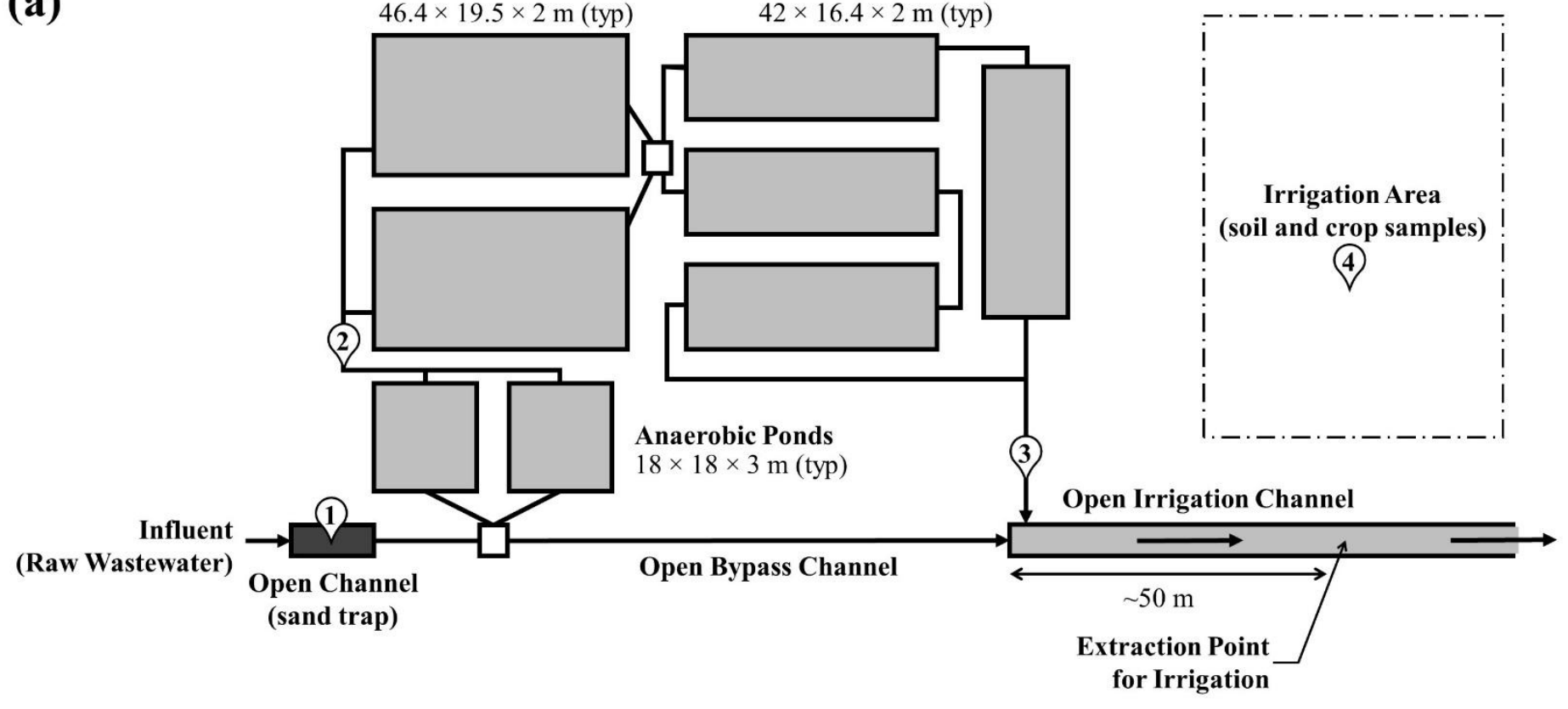

(b)

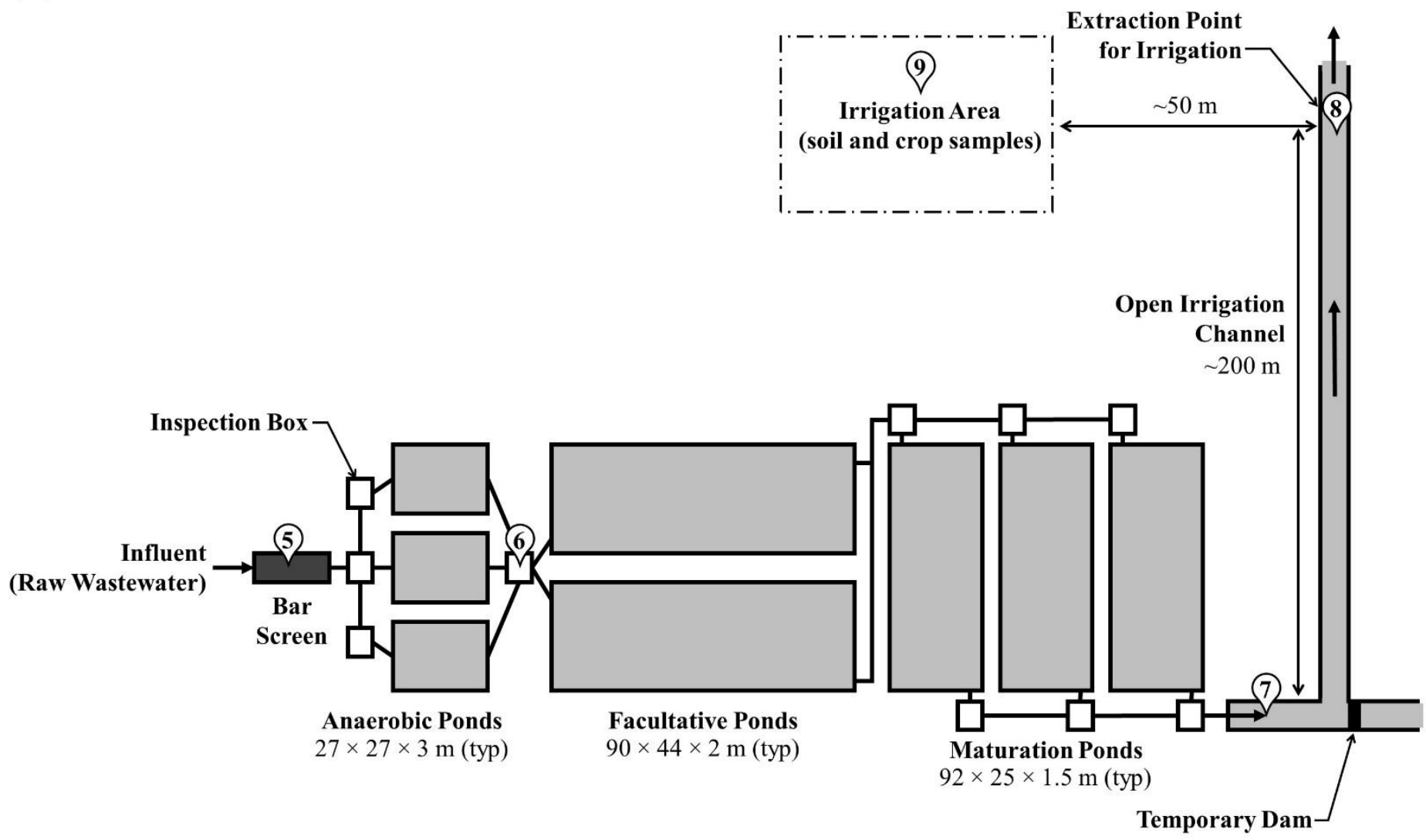

Figure 1. Schematic showing the nine sampling locations for the a) Arani and b) Punata waste stabilization pond and irrigation systems (not to scale). 

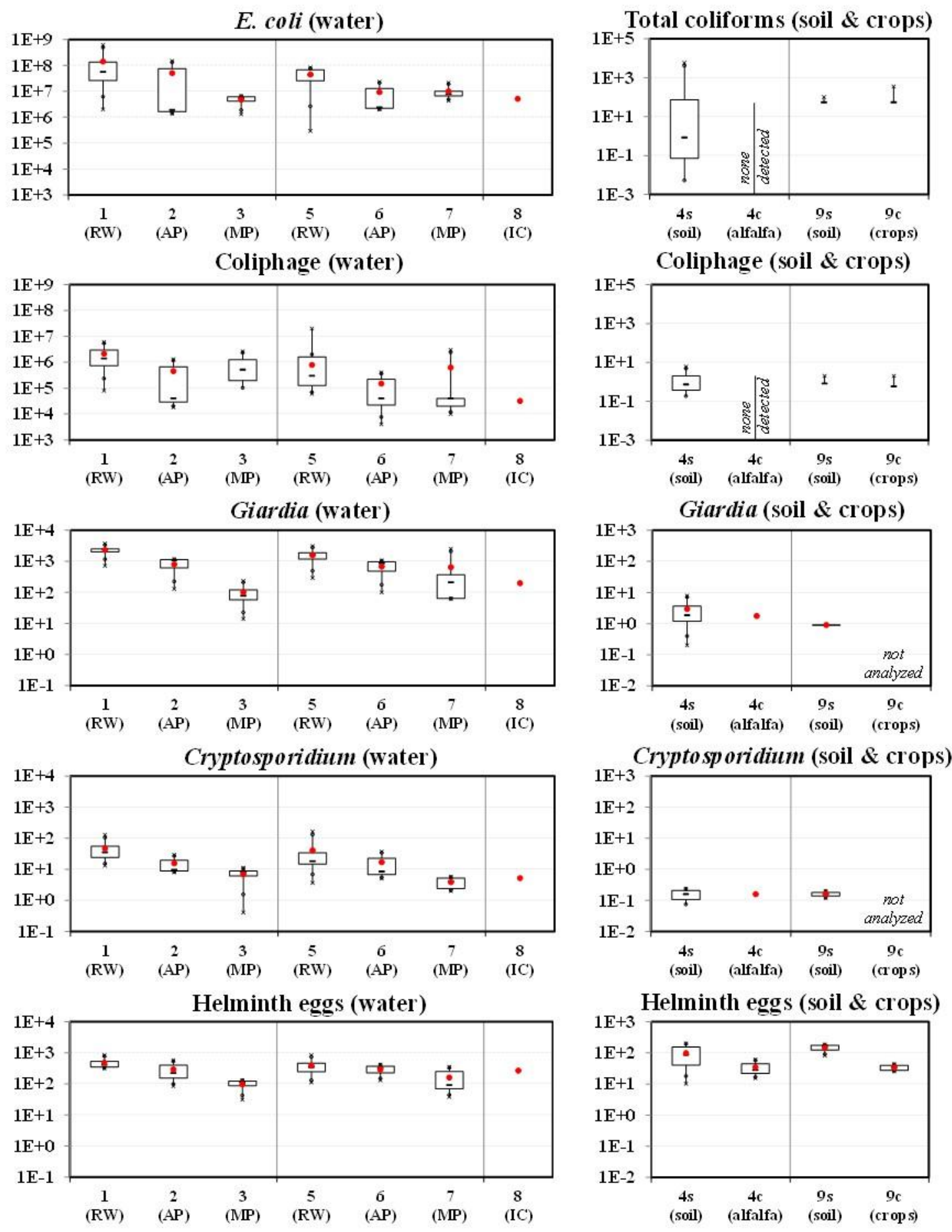

Minimum $/$ Maximum $\circ 5^{\text {th }}$ and $95^{\text {th }}$ percentile $\square$ Interquartile Range - Median $\quad$ Mean

Figure 2. Quantiles of the measured concentrations of $E$. coli (cfu), total coliforms (cfu), coliphage (pfu), Giardia (cysts), Cryptosporidium (oocysts), and helminth eggs (eggs) in water, soil, and crop samples from the waste stabilization pond and irrigation systems in Arani (samples 1 - 4) and Punata (samples 5 - 9) (labeled on the $x$ axis). All concentrations are expressed per liter (water) or per gram (soil and crops). For samples in which no microorganisms were detected in any of the replicates, a black line is drawn between zero and the assay detection limit. $\mathrm{RW}=$ untreated sewage; $\mathbf{A P}=$ effluent of the anaerobic pond(s); $M P=$ effluent of the final maturation pond; IC = irrigation channel; $s=$ irrigated soil; $c=$ irrigated crops. 
(a)

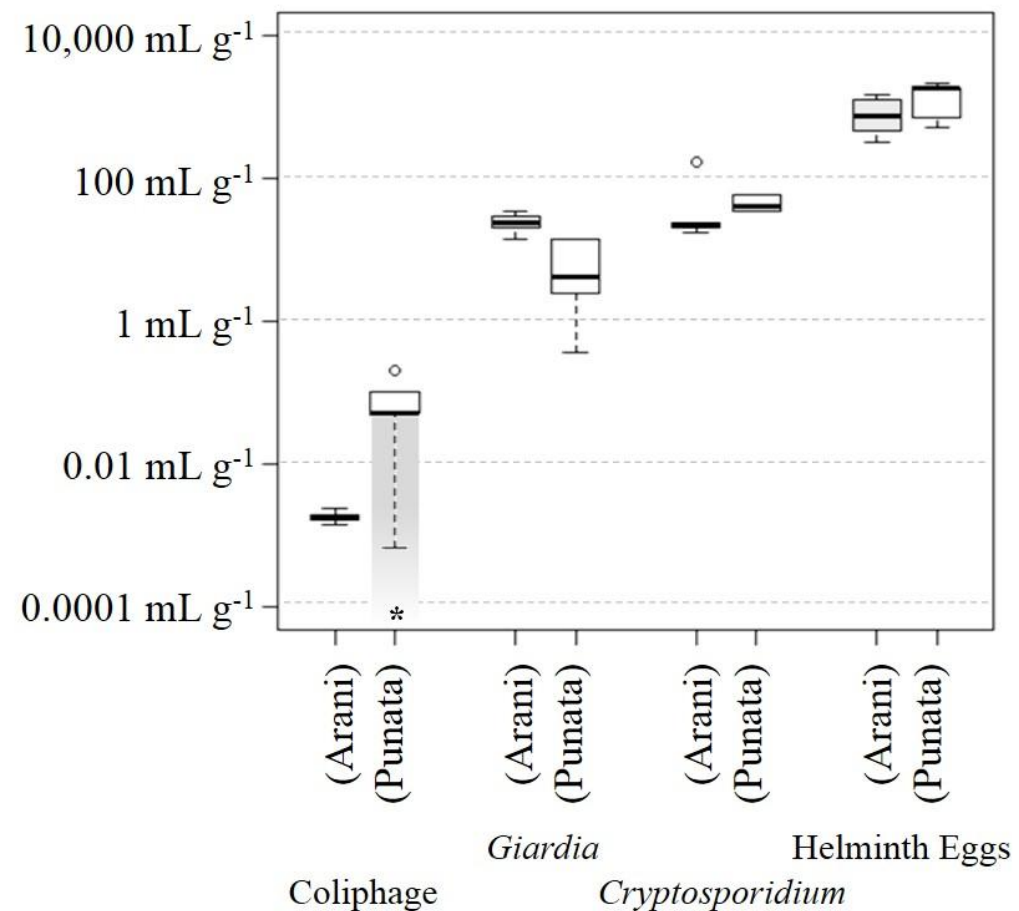

(b)

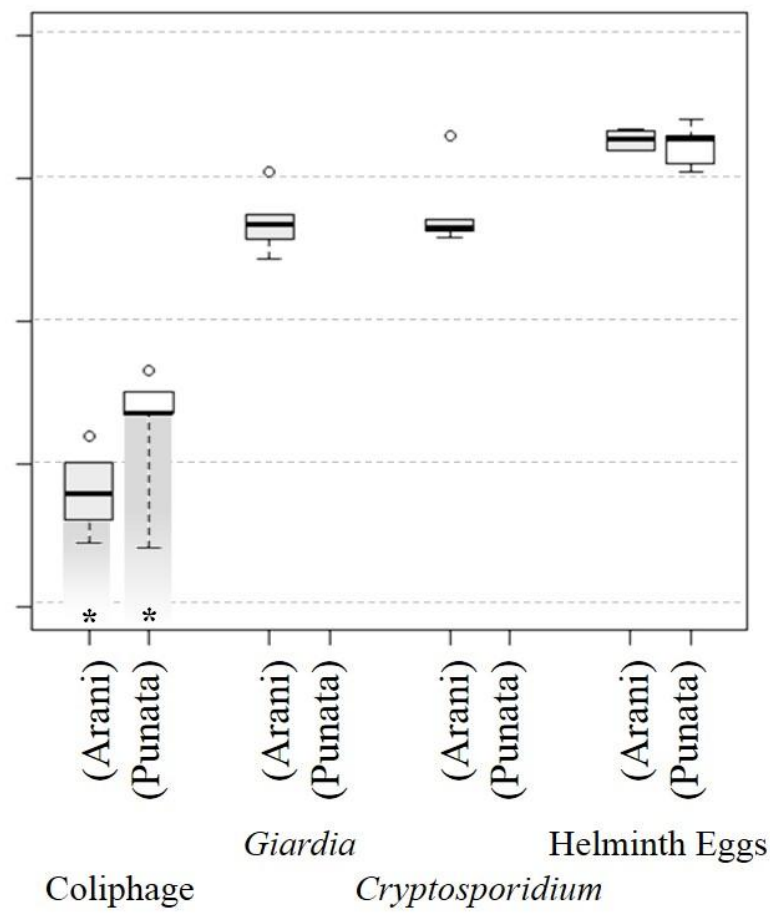

Figure 3. Ratios of the concentrations of coliphage, Giardia, Cryptosporidium, and helminth eggs in: a) soil relative to irrigation water; and b) crops relative to irrigation water. Units are $\mathrm{mL}^{-1}$. Ratios for coliphage marked with an asterisk (*) were calculated using the assay limit of detection. Because coliphages were either not detected in these samples or were only detected in one sample replicate at the limit of detection, the actual ratios may be lower. 
Table 1. Estimated $\log _{10}$ differences (and lower $95 \%$ confidence interval (LCI)) in the concentration of pathogens and fecal indicator organisms in water samples collected at the overall influent and effluent points of the Arani and Punata waste stabilization pond systems.

\begin{tabular}{lcc}
\hline & Arani WSP System & Punata WSP System \\
\hline E. coli & $1.1^{* *}$ & $0.7^{*}$ \\
Coliphage & $(95 \%$ LCI: 0.4$)$ & $(95 \% \text { LCI: }-0.1)^{\mathrm{a}}$ \\
& 0.2 & $1.0^{* *}$ \\
Giardia & $(95 \% \text { LCI: }-0.5)^{\mathrm{a}}$ & $(95 \%$ LCI: 0.2$)$ \\
& $1.5^{* * *}$ & $0.8^{*}$ \\
Cryptosporidium & $(95 \%$ LCI: 1.0$)$ & $(95 \%$ LCI: -0.1$)$ \\
& $0.7^{* * *}$ & $0.8^{* * *}$ \\
Helminth Eggs & $(95 \%$ LCI: 0.4$)$ & $(95 \%$ LCI: 0.4$)$ \\
& $(95 \%$ LCI: 0.5$)$ & $0.5^{* * *}$
\end{tabular}

*Wilcoxon location shift $\left(\log _{10}\right.$ removal) significantly greater than zero at the $10 \%$ level

${ }^{* *}$ Wilcoxon location shift $\left(\log _{10}\right.$ removal) significantly greater than zero at the $5 \%$ level

*** Wilcoxon location shift ( $\log _{10}$ removal) significantly greater than zero at the $1 \%$ level

${ }^{a}$ Negative values would indicate an increase in the concentration 